\title{
ChemComm
}

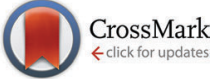

Cite this: Chem. Commun., 2016, 52, 7036

Received 11th April 2016,

Accepted 5th May 2016

DOI: $10.1039 / \mathrm{c} 6 \mathrm{cc} 03010 f$

www.rsc.org/chemcomm

\section{A solvothermal method for synthesizing monolayer protected amorphous calcium carbonate clusters $\dagger$}

\author{
Shengtong Sun, $\ddagger$ Denis Gebauer and Helmut Cölfen*
}

\begin{abstract}
A solvothermal method was developed for synthesizing organic monolayer protected amorphous calcium carbonate clusters using 10,12-pentacosadiynoic acid as ligand, ethanol as solvent and $\mathrm{NaHCO}_{3}$ decomposition as $\mathrm{CO}_{2}$ source, which can be extended to synthesize other monolayer protected mineral clusters.
\end{abstract}

Monolayer protected clusters (MPCs) have attracted great interest for a number of years since the pioneering work of Schiffrin and coworkers in the preparation of alkanethiolate monolayer protected gold clusters. ${ }^{1}$ Differing from colloidal particles prepared by other routes such as microemulsion ${ }^{2}$ or polymer stabilization, ${ }^{3}$ alkanethiolate or alkanecarboxylate MPCs are stable in air and can be repeatedly isolated from, and redissolved in common organic solvents without irreversible aggregation or decomposition. ${ }^{4}$ This property of MPCs opens up tremendous opportunities where they can be handled like 'molecules', and with it, MPCs have gained a variety of applications in catalysis, sensors, optical devices, electrochemistry, bioimaging, in superlattices, etc. ${ }^{5}$ Nevertheless, until now, the chemical compositions of MPCs are limited to metals such as $\mathrm{Au}, \mathrm{Ag}, \mathrm{Cu}, \mathrm{Pt}, \mathrm{Pd}$, etc., which narrows their applicability in a vast amount of scientific and industrial fields.

Apart from the well-known metals, minerals are also an important class of nanomaterials. ${ }^{6}$ Among them, calcium carbonate $\left(\mathrm{CaCO}_{3}\right)$ likely is the most important example, as it is abundant in nature as geological mineral and biomineral. For example, $\mathrm{CaCO}_{3}$ is the main component of limestone, mollusc shells, water scale and also participates in the geological $\mathrm{CO}_{2}$ cycle. In particular, $\mathrm{CaCO}_{3}$ provides a model system to study

Department of Chemistry, Physical Chemistry, University of Konstanz, Universitätsstrasse 10, Box 714, D-78457 Konstanz, Germany.

E-mail: helmut.coelfen@uni-konstanz.de

$\dagger$ Electronic supplementary information (ESI) available: Experimental details and Fig. S1-S4. See DOI: 10.1039/c6cc03010f

¥ Current address: School of Chemical Engineering, State Key Laboratory of Chemical Engineering, Shanghai Key Laboratory of Multiphase Materials Chemical Engineering, East China University of Science and Technology, 130 Meilong Road, Shanghai 200237, P. R. China. nucleation and crystallization of minerals. ${ }^{7}$ Controlling the size of $\mathrm{CaCO}_{3}$ is important in biomineralization ${ }^{8}$ and also in industry due to the high surface area and increased compatibility with matrix materials when the size is very small. Countless investigations have been undertaken to stabilize $\mathrm{CaCO}_{3}$ nanoparticles at different sizes and with various morphologies. ${ }^{6 c}$ However, due to the inherent severe ionic association, precise size control of $\mathrm{CaCO}_{3}$ nanoparticles at the nanoscale is quite challenging, and there are only a few reports on dispersible ultrafine $\mathrm{CaCO}_{3}$ particles. ${ }^{9}$ For instance, a complex liquid/solid/gas poly-phase reaction was used to produce overbased calcium alkylaryl sulfonate colloidal particles of 5-20 nm consisting of an organic shell and $\mathrm{CaCO}_{3} / \mathrm{Ca}(\mathrm{OH})_{2}$ hybrid core, which have already been commercialized as detergents. ${ }^{9 a-c}$ In addition, high-gravity reactive precipitation can provide massive yields of calcite nanoparticles in a size range of $17-36 \mathrm{~nm} .{ }^{9 d}$ Buchold et al. employed a microemulsion approach to synthesize monodisperse non-agglomerated $\mathrm{CaCO}_{3}$ nanoparticles with a size of $25 \mathrm{~nm} .{ }^{9 e}$ On the other hand, non-agglomerated $\mathrm{CaCO}_{3}$ vaterite nanoparticles ranging from 20 to $60 \mathrm{~nm}$ were obtained by a wet-chemical method with heating a dispersion of calcium bicarbonate in ethylene glycol. ${ }^{9 f}$ Additivefree monodisperse amorphous calcium carbonate (ACC) nanoparticles in the range of $100-200 \mathrm{~nm}$ were also produced in ethanol. ${ }^{9 g}$ None of previous efforts, however, has downsized $\mathrm{CaCO}_{3}$ entities to the subnanometer level or even clusters. Interestingly, the recently proposed "non-classical" nucleation pathway has already proven the existence of rather small $\mathrm{CaCO}_{3}$ pre-nucleation clusters with a size of $0.6-2 \mathrm{~nm} .{ }^{7,10}$ This indicates that it should be possible to stabilize such small $\mathrm{CaCO}_{3}$ entities by proper ligands to produce monolayer protected $\mathrm{CaCO}_{3}$ clusters rather than stabilizing them in situ by association with inorganic silica. ${ }^{11}$

In this paper, we show that an easy solvothermal method can be utilized to fabricate monolayer protected ACC clusters using 10,12-pentacosadiynoic acid (PCDA) as the ligand. The chemical structure of PCDA and experimental set-up are presented in Fig. 1a and b. In brief, to a mixed ethanolic solution of $10 \mathrm{mM} \mathrm{CaCl}_{2}, 4 \mathrm{mM}$ PCDA and $42 \mathrm{mM} \mathrm{NH}_{4} \mathrm{OH}, 2$ equimolar solid $\mathrm{NaHCO}_{3}$ was added. Then, the solution was tightly sealed 
a)
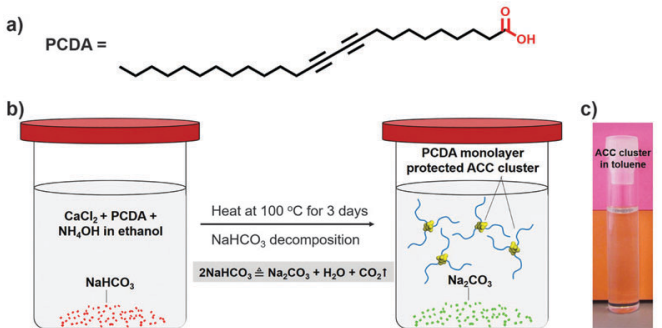

Fig. 1 (a) Chemical structure of PCDA. (b) Experimental set-up of solvothermal reaction for synthesizing PCDA monolayer protected amorphous $\mathrm{CaCO}_{3}$ (ACC) clusters. (c) The photo of PCDA monolayer protected ACC clusters in toluene.

and put in an oil bath at $100{ }^{\circ} \mathrm{C}$ for 3 days. Two main reactions successively occurred as follows:

$$
\begin{gathered}
2 \mathrm{NaHCO}_{3} \triangleq \mathrm{Na}_{2} \mathrm{CO}_{3}+\mathrm{H}_{2} \mathrm{O}+\mathrm{CO}_{2} \uparrow \\
\mathrm{CaCl}_{2}+\mathrm{CO}_{2}+\mathrm{NH}_{4} \mathrm{OH} \rightarrow \mathrm{CaCO}_{3} \cdot x \mathrm{H}_{2} \mathrm{O}(\mathrm{ACC})+\mathrm{NH}_{4} \mathrm{Cl}
\end{gathered}
$$

At $100{ }^{\circ} \mathrm{C}, \mathrm{NaHCO}_{3}$ can gradually decompose to release $\mathrm{CO}_{2}$, which serves for the formation of $\mathrm{CaCO}_{3}$. The occurrence of $\mathrm{NaHCO}_{3}$ decomposition was confirmed by the powder X-ray diffraction (XRD) and thermal gravimetric analyses (TGA) of the final solid residues (Fig. S1 and S2, ESI $\dagger$ ). We used ethanol as the solvent because it can both dissolve organic ligands and assist the formation of kinetically stable ACC. ${ }^{9 g, 12}$ Once very small ACC clusters formed in the solution, PCDA could effectively protect them against agglomeration. PCDA is found to be highly specific, while other long-chain alkyl ligands like stearic acid do not show a decisive stabilizing effect. After centrifugation, the collected solid was dissolved in toluene with the assistance of sonication. Thereby, only PCDA protected ACC clusters were dissolved, while insoluble $\mathrm{Na}_{2} \mathrm{CO}_{3}$ was removed by filtration. Further purification of the product by repeated cycles of dissolution in toluene and precipitation in ethanol finally gave pure PCDA monolayer protected ACC clusters. The solution of clusters in toluene is totally transparent (Fig. 1c), indicating the very small size of $\mathrm{CaCO}_{3}$. Like metal MPCs, PCDA monolayer protected ACC clusters can be repeatedly isolated from, and dissolved in organic solvents such as toluene, hexane, chloroform, dichloromethane, etc.

TEM (Fig. 2a and b) shows that the PCDA monolayer protected clusters are monodisperse with a mean size of $4.9 \mathrm{~nm}$ according to the size distribution histogram in Fig. 2d, which is also evidenced by dynamic light scattering (DLS) results (Fig. S3, ESI $\dagger$ ). Due to the interdigitation of hydrophobic PCDA chains, the clusters tend to aggregate during drying. The selected area electron diffraction pattern (Fig. 2c) shows no crystalline features indicating the amorphous nature of the clusters. To prove the presence of $\mathrm{Ca}$, we also performed energy dispersive X-ray (EDX) analysis. As shown in Fig. 2e, a signal for $\mathrm{Ca}$ is observable.

To obtain knowledge of the cluster structure, we compared the UV-vis and FTIR spectra of PCDA and PCDA protected ACC clusters, as presented in Fig. 3. Upon attachment to the ACC core, PCDA chains in the shell exhibit similar UV absorption peaks from diacetylene groups (Fig. 3a), revealing that they do
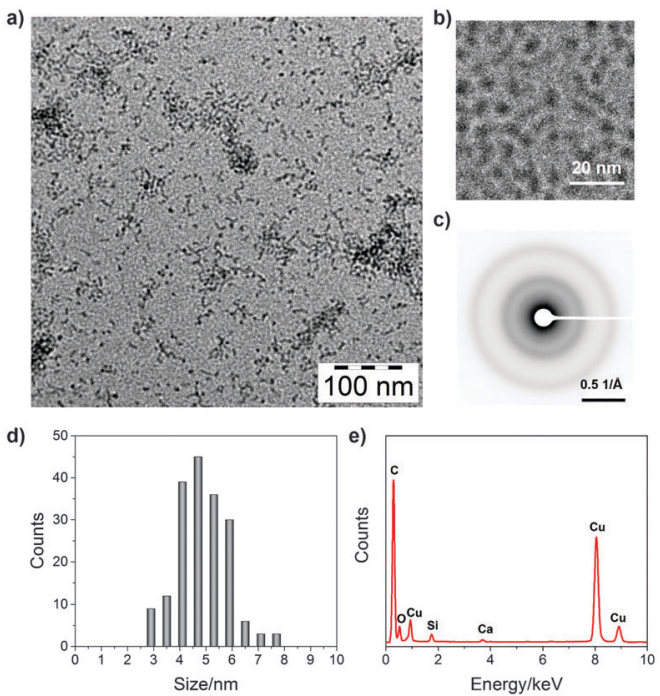

Fig. 2 (a) TEM, (b) high-resolution TEM images and corresponding (c) electron diffraction of PCDA monolayer protected ACC clusters. Electron diffraction was obtained from a round area with a diameter of $200 \mathrm{~nm}$ in (a). (d) Size distribution of the clusters by counting 180 particles in (a). (e) EDX profile of PCDA monolayer protected ACC clusters showing the presence of $\mathrm{Ca}$. Note that the signal for $\mathrm{Si}$ comes from the detector, and for $\mathrm{C}$ and $\mathrm{Cu}$, from the carbon coated copper grid.

not change significantly as a ligand of $\mathrm{CaCO}_{3}$. This is important, since PCDA is a light-sensitive monomer which can easily polymerize even upon room light irradiation. ${ }^{13}$ No obvious absorption in the visible region can be observed, which shows absence of polymerization and accords well with the good transparency of the cluster solution. The FTIR spectrum of PCDA protected ACC cluster in Fig. 3b shows features of PCDA and ACC. For instance, the $\mathrm{C}-\mathrm{H}$ stretching bands arise from the PCDA shell. The stretching band of $\mathrm{C}=\mathrm{O}$ shifts from $1690 \mathrm{~cm}^{-1}$ for $\mathrm{COOH}$ in PCDA to $1547 \mathrm{~cm}^{-1}$ for $\mathrm{COO}^{-}$in the cluster, indicating that PCDA chains bind on the ACC core by the chelation between terminal carboxylate groups and $\mathrm{Ca}$ ions. The broad band between 3600 and $3000 \mathrm{~cm}^{-1}$ indicates the presence of structural water in the cluster, which is consistent with the amorphous nature of the $\mathrm{CaCO}_{3}$ core. ${ }^{12}$ Moreover, the $\nu_{1}-\nu_{4}$ bands of carbonate ions characteristic for $\mathrm{ACC}^{14}$ can also be identified.

TGA and matrix-assisted laser desorption/ionization time-offlight mass spectroscopy (MALDI-TOF MS) measurements were
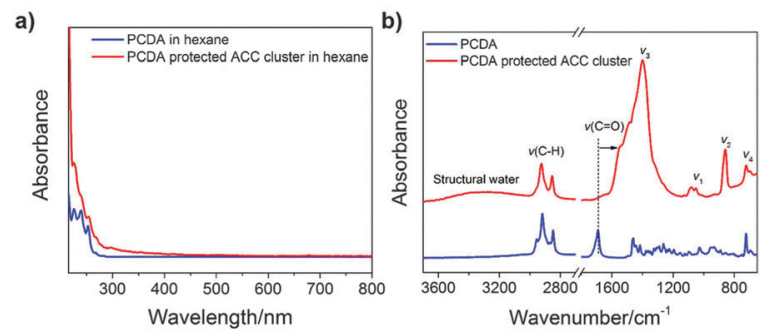

Fig. 3 (a) UV-vis spectra of PCDA and PCDA protected ACC clusters in hexane. (b) ATR-FTIR spectra of PCDA crystals and dried PCDA protected ACC cluster. 


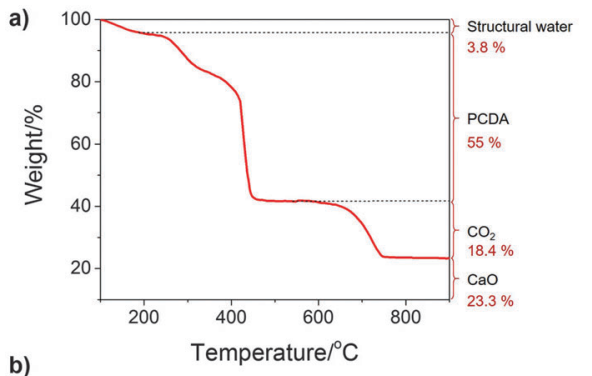

b)

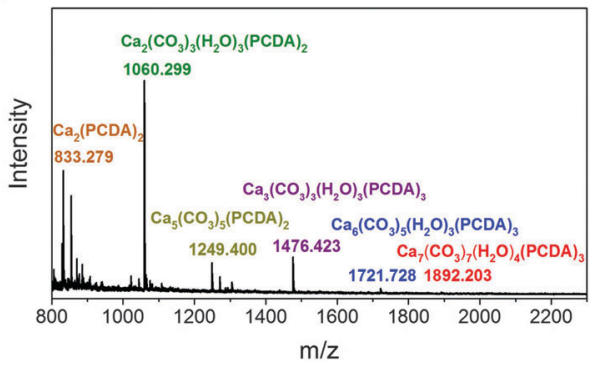

Fig. 4 (a) TGA curve (air flow) and (b) MALDI-TOF MS spectrum of PCDA monolayer protected ACC clusters. Corresponding assignments of main dissociated species are also presented. Note that the probable presence of $\mathrm{HCO}_{3}{ }^{-}$and $\mathrm{OH}^{-}$may bring an uncertainty of 1-3 $\mathrm{Da}$ between calculated and experimental data.

performed to explore the chemical composition of PCDA monolayer protected ACC clusters (Fig. 4). Under air-flow, the TGA trace reveals successive mass losses due to the removal of structural water, PCDA degradation and $\mathrm{CaCO}_{3}$ decomposition (Fig. 4a). The corresponding atomic ratio of $\left[\mathrm{CaCO}_{3}\right]:\left[\mathrm{H}_{2} \mathrm{O}\right]:[\mathrm{PCDA}]$ was calculated to be $2.8: 1.4: 1$. When compared to synthetic ACC with a typical formula of $\mathrm{CaCO}_{3} \cdot \mathrm{H}_{2} \mathrm{O},{ }^{14-15}$ in the PCDA protected ACC cluster, the number of structural $\mathrm{H}_{2} \mathrm{O}$ is only half of that of $\mathrm{CaCO}_{3}$. Indeed, according to simulation results, $N_{\text {water }} / N_{\text {Ca }}$ decreases drastically as the size of ACC decreases in the lower nanometer level $(<1.5 \mathrm{~nm}) .{ }^{16}$ The composition is also in accord with the MALDI-TOF MS spectrum (Fig. 4b). The assignments of the main dissociated species reveal that the maximum number of $\mathrm{CaCO}_{3}$ units in the clusters is 7, whereas the number of structural water molecules varies, with a maximum of 4 , and the number of PCDA chains is always smaller than 3. As the ionization process leads to the dissociation of most clusters, the formula $\left(\mathrm{CaCO}_{3}\right)_{7}\left(\mathrm{H}_{2} \mathrm{O}\right)_{4}(\mathrm{PCDA})_{3}$ should represent the actual composition of the PCDA monolayer protected ACC cluster, which agrees well with the atomic ratio calculated from TGA. An ACC structure with about $7 \mathrm{CaCO}_{3}$ units has a size of $\sim 1 \mathrm{~nm}$ according to previous molecular simulation. ${ }^{16}$ The fully stretched PCDA molecule with a rigid all-trans conformation has a size of about $3 \mathrm{~nm}$-based on TEM investigations, however, the PCDA chains in the cluster are assumed to adopt a curved gauche conformation with an average size of 1.5-2 nm. The models for the all-trans and gauche conformations of PCDA chains are also presented (Fig. S4, ESI $\dagger$ ).

In summary, we discovered a solvothermal method to prepare monolayer protected amorphous $\mathrm{CaCO}_{3}$ clusters using PCDA as the ligand, ethanol as the solvent, and $\mathrm{NaHCO}_{3}$ decomposition as $\mathrm{CO}_{2}$ source. The resulting clusters with an average size of $\sim 4.9 \mathrm{~nm}$ show very good stability and transparency in toluene and can be repeatedly precipitated from, and dissolved in common organic solvents, like typical MPCs based on metals. Structural characterizations suggest that the cluster has a hydrated ACC core and an organic PCDA shell with gauche conformations. The chemical formula of the cluster was estimated to be $\left(\mathrm{CaCO}_{3}\right)_{7}\left(\mathrm{H}_{2} \mathrm{O}\right)_{4}(\mathrm{PCDA})_{3}$. Our method presented here extends the scope of MPCs, and its potential to be applied to the synthesis of mineral MPCs.

S. T. S. gratefully acknowledges the financial support from Alexander von Humboldt Foundation. D. G. is a Research Fellow of the Zukunftskolleg of the University of Konstanz, and supported by the Fonds der Chemischen Industrie. The authors thank Zhouyue Lei (Fudan University, China) for supplementary experiments.

\section{Notes and references}

1 (a) M. Brust, M. Walker, D. Bethell, D. J. Schiffrin and R. Whyman, J. Chem. Soc., Chem. Commun., 1994, 801-802; (b) M. Brust, J. Fink, D. Bethell, D. J. Schiffrin and C. Kiely, J. Chem. Soc., Chem. Commun., 1995, 1655-1656.

2 (a) I. Capek, Adv. Colloid Interface Sci., 2004, 110, 49-74; (b) A. LedoSuárez, J. Rivas, C. F. Rodríguez-Abreu, M. J. Rodríguez, E. Pastor, A. Hernández-Creus, S. B. Oseroff and M. A. López-Quintela, Angew. Chem., Int. Ed., 2007, 46, 8823-8827.

3 (a) M. Zhao, L. Sun and R. M. Crooks, J. Am. Chem. Soc., 1998, 120, 4877-4878; (b) J. Xie, Y. Zheng and J. Y. Ying, J. Am. Chem. Soc., 2009, 131, 888-889.

4 A. C. Templeton, W. P. Wuelfing and R. W. Murray, Acc. Chem. Res., 1999, 33, 27-36.

5 (a) Y. Lu and W. Chen, Chem. Soc. Rev., 2012, 41, 3594-3623; (b) T.-Y. Dong, H.-H. Wu and M.-C. Lin, Langmuir, 2006, 22, 6754-6756. 6 (a) M. F. Hochella, S. K. Lower, P. A. Maurice, R. L. Penn, N. Sahai, D. L. Sparks and B. S. Twining, Science, 2008, 319, 1631-1635; (b) J. Rieger, M. Kellermeier and L. Nicoleau, Angew. Chem., Int. Ed., 2014, 53, 12380-12396; (c) Y. Boyjoo, V. K. Pareek and J. Liu, J. Mater. Chem. A, 2014, 2, 14270-14288.

7 (a) D. Gebauer, A. Völkel and H. Cölfen, Science, 2008, 322, 1819-1822; (b) D. Gebauer, M. Kellermeier, J. D. Gale, L. Bergström and H. Cölfen, Chem. Soc. Rev., 2014, 43, 2348-2371.

8 (a) A.-W. Xu, Y. Ma and H. Cölfen, J. Mater. Chem., 2007, 17, 415-449; (b) F. C. Meldrum and H. Cölfen, Chem. Rev., 2008, 108, 4332-4432. 9 (a) J. Mansot, M. Hallouis and J. Martin, Colloids Surf., A, 1993, 71, 123-134; (b) L. Cizaire, J. Martin, T. Le Mogne and E. Gresser, Colloids Surf., A, 2004, 238, 151-158; (c) Y. Chevalier, A. Chivé, B. Delfort, M. Born, L. Barré and R. Gallo, Prog. Colloid Polym. Sci., 2000, 100-105; (d) J.-F. Chen, Y.-H. Wang, F. Guo, X.-M. Wang and C. Zheng, Ind. Eng. Chem. Res., 2000, 39, 948-954; (e) D. H. M. Buchold and C. Feldmann, Adv. Funct. Mater., 2008, 18, 1002-1011; $(f)$ T. Schuler and W. Tremel, Chem. Commun., 2011, 47, 5208-5210; (g) S.-F. Chen, H. Cölfen, M. Antonietti and S.-H. Yu, Chem. Commun., 2013, 49, 9564-9566.

10 E. M. Pouget, P. H. H. Bomans, J. Goos, P. M. Frederik, G. de With and N. Sommerdijk, Science, 2009, 323, 1455-1458.

11 M. Kellermeier, D. Gebauer, E. Melero-Garcia, M. Drechsler, Y. Talmon, L. Kienle, H. Cölfen, J. M. Garcia-Ruiz and W. Kunz, Adv. Funct. Mater., 2012, 22, 4301-4311.

12 H. S. Lee, T. H. Ha and K. Kim, Mater. Chem. Phys., 2005, 93, 376-382.

13 O. Yarimaga, J. Jaworski, B. Yoon and J.-M. Kim, Chem. Commun., 2012, 48, 2469-2485.

14 D. Gebauer, P. N. Gunawidjaja, J. Y. P. Ko, Z. Bacsik, B. Aziz, L. J. Liu, Y. F. Hu, L. Bergström, C. W. Tai, T. K. Sham, M. Edén and N. Hedin, Angew. Chem., Int. Ed., 2010, 49, 8889-8891.

15 J. Ihli, W. C. Wong, E. H. Noel, Y. Y. Kim, A. N. Kulak, H. K. Christenson, M. J. Duer and F. C. Meldrum, Nat. Commun., 2014, 5, 3169.

16 P. Raiteri and J. D. Gale, J. Am. Chem. Soc., 2010, 132, 17623-17634. 